Est Ag 48 (2013) 5-17

\title{
¿Cristianismo o cristianismos? EI caso del evangelio de Judas
}

\author{
P. Prosper Grech, OSA ${ }^{1}$
}

RESUMEN: Hoy día ha cobrado impulso la teoría de que en los primeros siglos del cristianismo convivieron varias formas de cristianismo y que sólo a partir de s. IV se configuró un único cristianismo, mientras las otras tradiciones fueron silenciadas. Frente a esta teoría, el Cardenal Grech expone un caso concreto: El Evangelio de Judas. En él, el verdadero héroe es Judas, amigo de Jesús, que sustituye a Pedro y a Juan, pero aquí el evangelio ya no tiene por referencia una norma fidei sino una gnosis a cuyo servicio se proclama. Por eso, este evangelio no es una herejía del cristianismo porque su regula fidei es la gnosis. Para ver el contraste, lo mejor es analizar el caso de la iglesia de Éfeso donde confluyen una serie de teologías y tradiciones como la petrina, joánica y la paulina, y sin embargo, hay un solo cristianismo que incluso es previo a los escritos que luego formarían el Nuevo Testamento.

Palabras clave: Evangelio de Judas, Nuevo Testamento, tradiciones cristianas, regula fidei, gnosis.

\footnotetext{
${ }^{1}$ El Padre Grech, como a él le gusta que le sigamos llamando, fue creado Cardenal de la Iglesia por el Papa Benedicto XVI a principios del año 2012. Durante gran parte de su vida ha sido profesor de Sagrada Escritura, y miembro de la Congregación para la Doctriana de la Fe desde 1984. Fue socio cofundador, con el P. Agustín Trapé, del Instituto Patrístico Agustiniano de Roma, un centro de referencia internacional para el Estudio de los Padres de la Iglesia. La conferencia que publicamos fue la Lección Inaugural del curso 2012-2013 en el Estudio Teológico Agustiniano de Valladolid.
} 
ABSTRACT: Today it has gained more followers the theory that various forms of Christianity coexisted in the first centuries and only from IVth century on, Christianity became a unique set, while the other traditions were silenced. Against these theory, Cardinal Grech exposes a particular case: The Gospel of Judas. In this apocryphal Gospel, the real hero is Judas, who replaced Peter and John as Jesus's closest friends. But this Gospel has not as reference a norma fidei but the gnosis, in whose service it is proclaimed. To see the contrast, the better way is to analyze the case of the church of Ephesus where several theologies and traditions (as the Petrine, Johannine and Pauline) converge, but nevertheless there is only one Christianity which is even prior to the writtings what became later the New Testament.

Keywords: Gospel of Judas, New Testament, Christian traditions, regula fidei, gnosis.

El título de un reciente libro de Bart D. Ehrman, Cristianismos perdidos: Los credos proscritos del Nuevo Testamento, publicado en inglés en 2003, y traducido, entre otros idiomas, al castellano en 2004, plantea tres graves problemas que están encontrando amplio eco: a) la equiparación, en los primeros siglos, de los diferentes sistemas gnósticos con el cristianismo oficial; b) el criterio de distinción entre ortodoxia y herejía; c) el valor del canon del Nuevo Testamento como norma de discernimiento entre los libros que establecen la fe cristiana. Es evidente que el impulso para estas ideas proviene de la obra clásica de Walter Bauer, Rechtgläubigkeit und Ketzerei im ältesten Christentum de 1934.

La tesis de este autor es bien conocida entre los estudiosos. Después de analizar la situación teológica de las diversas iglesias, el autor concluye que en los dos o tres primeros siglos, las doctrinas que ahora llamamos heréticas, precedieron a las que actualmente se estiman como ortodoxas. La susodicha ortodoxia fue impuesta desde y por Roma, apoyándose en Corinto, también con medios económicos caritativos, como puente para difundir las doctrinas romanas en el este. El mono-episcopado y el canon del Nuevo Testamento fueron valiosas herramientas en manos de la iglesia de Roma para lograr el propósito de exigir e imponer una fe unitaria, eliminando todo tipo de competencia.

La tesis de Bauer fue muy criticada, tanto por el frecuente uso del argumento ex silentio, como por la interpretación distorsionada de los documentos. Pero, en última instancia, se fue abriendo camino, como frecuentemente suele suceder con propuestas extremistas. El descubrimiento de los 
manuscritos de Nag Hammadi en 1947 y los estudios sobre el gnosticismo que siguieron, aunque sustancialmente añadieron poco a lo que ya sabíamos por parte de la literatura patrística anti-herética, fueron empleados para volver a reavivar las ideas de Bauer. En consecuencia, hoy está cobrando impulso la teoría de que en los primeros siglos convivieron y coexistieron diferentes cristianismos eiusdem iuris y que sólo a partir del siglo tercero o cuarto se puede hablar de un cristianismo único.

Comencemos clarificando las cosas: la visión de estos estudiosos considera la historia de forma fenomenológica y sitúa en un mismo plano el paulinismo, las corrientes joánicas, Santiago, el gnosticismo y el judeo-cristianismo como versiones legítimas del cristianismo, como vías paralelas sin ningún tipo de distinción entre la interpretación correcta e incorrecta de Cristo. Sólo las vicisitudes de la historia o el destino otorgaron la victoria al cristianismo tradicional, pero algunos sistemas anatematizados en la antigüedad se pueden recuperar y considerar hoy como cristianismos legítimos. El canon debería ser revisado, incluyendo libros que fueron desestimados en su día por ser poco ortodoxos.

Sin embargo, el problema del gnosticismo no es tan sencillo: ¿los sistemas gnósticos son religiones paralelas pero sin relación con el cristianismo o, por el contrario, son herejías del cristianismo? Varios autores modernos los consideran históricamente como una herejía cristiana, pero si examinamos en detalle los códices de Nag Hammadi, algunos manuscritos no contienen nada que pueda ser catalogado como cristiano, mientras que otros documentos, partiendo del cristianismo y tomando elementos judíos, construyen sus propios sistemas. Quienes defienden que el gnosticismo era una herejía cristiana, entonces consideran que los códices sin rasgos cristianos fueron un producto tardío del gnosticismo, cuando el gnosticismo había sido prohibido y ya no tenía voz en el foro público. Yo soy de la opinión, sin embargo, de que el gnosticismo surgió a partir de una mezcla de franjas marginales de la filosofía platónica, del judaísmo heterodoxo y de ideas cristianas todavía inmaduras; como ciertas teosofías modernas, p.e. la Nueva Era (New Age), son sistemas eclécticos en los que confluyen elementos cristianos, orientales y filosóficos. Por tanto, aunque incorporaban elementos cristianos en su sistema, algunos gnósticos no se consideraban en absoluto cristianos, sino pertenecientes a una religión paralela; otros, sin embargo, habrían confesado y proclamado que eran cristianos.

Es evidente que la formación del canon del Nuevo Testamento, fuera éste una imposición o un producto espontáneo de la tradición cristiana, operó un discernimiento entre ortodoxia y heterodoxia. Si debiéramos hoy eliminar el canon aceptado por todos los cristianos, se crearía un estado de caos y un 
relativismo en el que cada escrito que mencionara a Jesús o a Cristo, reivindicaría el derecho de ser considerado cristiano.

El mismo problema se plantea con respecto a la distinción entre herejía y ortodoxia. Nadie puede negar que la ortodoxia ha sido un producto de diversas luchas dentro de la Iglesia; pero eso que ahora llamamos ortodoxia ¿nació de casuales factores políticos, sociales y religiosos, o por el contrario surgió de una exigencia interna a la misma naturaleza del cristianismo? ¿Se puede hablar de una ortodoxia inicial de la que se fueron separando corrientes heterodoxas o, por el contrario, todavía está en vigor la tesis de Bauer, según la cual esas heterodoxias primigenias fueron marginadas o prohibidas por grupos con mayor poder político?

Para responder adecuadamente a este cúmulo de cuestiones, serían necesarios varios volúmenes. Aquí expondremos un caso concreto, como es el evangelio de Judas, descubierto y publicado hace pocos años, lo que nos permitirá ampliar nuestras consideraciones y dar algunas respuestas a los cuestionamientos planteados en esta introducción.

El códice papiráceo Tchacos, que lleva el nombre de la anticuaria de Zurich que lo vendió a los estudiosos americanos, fue descubierto en 1978, robado y luego tuvo una historia rocambolesca que bien pudiera ser objeto de una película o novela de suspense, hasta el año 1982 cuando fue recuperado en un estado deplorable de conservación. Tras un largo periodo de restauración realizada por el profesor Passer y gracias a los medios de la ciencia moderna, se está ahora en la fase de realizar la edición crítica. El códice data de principios del siglo IV, o de antes, y contiene cuatro escritos gnósticos: una versión de la Carta de Pedro a Felipe (pp. 1 - 9), que corresponde al Códice VIII de Nag Hammadi; "Santiago" [el primer Apocalipsis de Santiago] (pp. 10 - 32) como en el Códice V de NH; el Evangelio de Judas (pp. 33 - 58), texto desconocido hasta entonces, pero mencionado por Ireneo $(A H \mathrm{I}, 31,1)$; y un escrito semejante al libro del Alógeno del Códice XI de NH.

El Evangelio de Judas, compuesto originalmente en griego, pero traducido a la lengua copta, data de la primera mitad del siglo II, tal vez hacia el año 150. Es un libro gnóstico; Ireneo lo sitúa en el contexto de los cainitas, pero pertenece más bien a la corriente setiana. El autor conoce nuestros evangelios, al menos la tradición sinóptica. El objeto de su escrito fue modificar la valoración que la ortodoxia hacía de esta tradición, convirtiendo para ello a Judas Iscariote en héroe, el discípulo elegido por Jesús, en detrimento de los doce representantes de la gran Iglesia, con quienes entra en una amarga polémica.

El libro se inicia con las palabras: "Discurso secreto del pronunciamiento mediante el que Jesús habló con Judas Iscariote, en ocho días, tres días 
antes de que él celebrara la Pascua". A diferencia de los evangelios canónicos, que se leían en público y en ámbito universal, la revelación a Judas es secreta, como la de los escritos gnósticos. El evangelio de Judas no concluye con la crucifixión y resurrección de Jesús, sino con la traición de Judas, que adquiere un significado salvífico en la cristología de este evangelio. Jesús "aparece en la tierra", realiza milagros para la salvación, elige a los doce apóstoles con los que a menudo aparece en forma de un niño (o aparición), por tanto un Jesús que sabe de docetismo. El propósito y los temas de sus conversaciones son los misterios ultramundanos y escatológicos, es decir, una revelación gnóstica del pléroma de donde él mismo procede.

Los doce confiesan: "Tú eres... el hijo de nuestro Dios" (EJ 35) como en Mc 8,27-30, pero Jesús se ríe de ellos porque el significado de la confesión es totalmente diferente a la de los sinópticos. El dios de los discípulos, es decir, de los seguidores de la Iglesia apostólica, no es el Dios supremo, sino Yaldabaoth o Nebro, el demiurgo creador de este mundo material. La tarea del Salvador será liberar, mediante sus revelaciones, a los gnósticos del engaño de este dios. La verdadera confesión de fe en Jesús, a diferencia de la de Pedro en los sinópticos, viene proferida por Judas: "Yo sé quién eres y de dónde has venido. Tú has venido del reino (eón) inmortal de Barbelo. Y yo no soy digno de pronunciar el nombre del que te envió" (EJ 36). Entonces él [Judas] fue elegido, pero Jesús le dice que deberá sufrir y ser reemplazado por otro (Matías en Hechos 1,15-26) antes de llegar al reino (EJ 36). Es una imagen, en negativo, de la confesión de Pedro.

La polémica más fuerte contra la gran Iglesia se encuentra en EJ 39-41, donde doce sacerdotes ofrecen sacrificios, contemplados en una visión por los apóstoles y explicada por Jesús; éstos representan a los líderes de la Iglesia y son acusados de extraviar a la gente y de ofrecer en sacrificio a sus propios hijos y esposas, de practicar la homosexualidad y de otros delitos, según como son guiados por sus propias estrellas. Ellos forman parte del semen [semillas] esparcido por Sofía sobre las rocas, de donde proviene la creación de los mortales corruptibles que no entrarán en el reino (EJ 45).

Judas, llamado el decimotercero, sin embargo, apedreado por los doce, representa a los gnósticos perseguidos por la Iglesia; estos perseguidores pertenecen a la categoría de los materiales y no pueden ser salvados. Sólo los espirituales, los gnósticos, se salvarán (EJ 45-47). En los números 48 [cuarenta y ocho] y 49 [cuarenta y nueve], la transfiguración de Mc 9 [nueve] se transfiere a Judas, quien recibe la revelación explicativa de los misterios gnósticos, comenzando desde la creación de Adán y Eva.

Por tanto, ¿cuál era la misión de Judas? Jesús la define en EJ 57 [cincuenta y siete]: "Tú los excederás a todos, pues sacrificarás al hombre que me 
porta. Ya tu cuerno se ha levantado, tu ira se ha colmado, tu estrella ha pasado y tu corazón se hace fuerte". En el contexto gnóstico, estas palabras significan que Judas era el hombre predestinado a traicionar a Jesús para liberarlo del cuerpo que ocultaba su verdadero ser del eón celeste y llevarlo de regreso al pléroma, al que pertenece. Como ya hemos indicado anteriormente, la historia de la crucifixión no viene narrada porque la muerte redentora de Cristo no juega ningún papel en el sistema gnóstico. Su cuerpo servía solamente para "portar" su ser verdadero de revelador, enviado para desentrañar los misterios del cielo a los espirituales, es decir, a los gnósticos. El lado oscuro del mundo no es el pecado, sino la ignorancia.

Judas, por tanto, no se deja seducir por el demonio, sino que es el amigo íntimo de Jesús y lo entiende mejor que nadie; es el verdadero héroe del evangelio, y sustituye a las figuras de Pedro y Juan de los evangelios canónicos.

La adopción del género literario de "evangelio" por parte de los gnósticos y la clara dependencia del Evangelio de Judas respecto a los evangelios que más tarde se denominarían canónicos, implica un reconocimiento de la autoridad que ya tenían éstos en la Iglesia desde el inicio del siglo segundo. Pero el tenor del relato y la teología de nuestros evangelios vienen cambiados e invertidos como si se pretendiese que una chaqueta harapienta por la parte interior fuera la forma correcta de vestirla. Esto nos lleva a la cuestión central de si podemos considerar este documento como cristiano o no.

¿Qué es lo que define a un escrito como cristiano? La pregunta tiene una respuesta fácil si tuviéramos que prescindir del criterio canónico y observar de forma aséptica y fenomenológica todos los grupos de los primeros siglos que reivindicaban este nombre para sí mismos. ¿Se podría decir que cristiano es un seguidor de Jesús de Nazaret, o uno que confiese que Jesús es el Cristo, el Salvador? Pero ¿de qué Jesús estamos hablando, del que nos presentan los cuatro Evangelios, los cuales ya nos ofrecen una interpretación confesional? ¿De un salvador gnóstico o más bien del Mesías de los ebionitas? El problema es a la vez histórico y epistemológico, porque las fuentes que poseemos, gnósticas, ebionitas, judías, romanas y eclesiásticas, presentan la figura de Jesús de diferentes formas. Si dijéramos, además, que cristiano es alguien que interpreta a Jesús conforme a la conciencia que tenía de sí mismo, chocaríamos contra las teorías de la Historia de las Formas (Formgeschichte) según las cuales la autoconciencia de Jesús en nuestros evangelios es una retro-proyección posterior de la fe de los evangelistas o de la comunidad. Parece que estamos, por tanto, ante un callejón sin salida. 
Intentar responder a todas estas cuestiones nos conduciría a un laberinto. Creo que el mejor método para encontrar una solución satisfactoria será intentar una reconstrucción de los inicios de la Iglesia siguiendo el camino de mayor probabilidad de lo sucedido con los datos que tenemos en la mano. Los primeros creyentes eran todos ellos judíos, enraizados en el estricto monoteísmo de la Biblia, seguidores de la Torá, convencidos de que las profecías bíblicas se estaban cumpliendo en torno a la persona de Jesús de Nazaret, muerto y resucitado. Cualquier sugerencia de que el Dios creador del mundo, salvador de Israel y dador de la ley no fuera el verdadero Dios, habría sido rechazada con desdén. Dentro de su judaísmo, se podían discutir las interpretaciones de la Biblia o sobre las novedades que había supuesto la nueva fe en Jesús el Mesías. Las primeras comunidades, tanto en Israel como en la diáspora, formaban pequeñas comunidades domésticas que seguían los pasos de su fundador, el apóstol, pero unidas entre sí por el bautismo y las sencillas profesiones de fe emitidas en ese momento. Los judíos denominaron a este grupo "nazarenos", pero pronto, con la incorporación de gentiles a sus comunidades, el nombre de cristianos los calificó ante griegos y romanos. Para entender mejor las diferencias de la identidad cristiana, tomamos como ejemplo la ciudad de Éfeso, el centro del cristianismo en Asia Menor. Cuando Ignacio de Antioquía pasó por esa ciudad, hacia el año 107, existían comunidades de tradición paulina, otras que podemos denominar “joánicas” y, tras la huida de muchos cristianos de Judea en el año 70, también existían grupos cristianos judíos observantes de la ley. Sin embargo, había un único obispo, elogiado por Ignacio. El mono-episcopado, ya existente anteriormente en Siria, se estaba propagando en Asia y más tarde llegaría también a Roma. Cuando el autor del Apocalipsis dirige su breve carta profética a los Efesios, en el capítulo 2, parece que no la dirije solamente a los jóvenes, sino a todos los creyentes, y hace hincapié en la observancia de las reglas del denominado Concilio de Jerusalén, quizás descuidadas por algunos miembros cristianos de tradición paulina. Incluso Ignacio, en su carta a los Efesios, se dirige a toda la comunidad, con un fuerte énfasis en la aceptación del obispo como único dirigente. Es posible que algunos cristianos de tradición carismática provenientes de las comunidades joánicas, no estuvieran plenamente convencidos del papel del obispo. Encontramos, por tanto, concepciones diferentes en esa ciudad. Diferencias sí, pero no tenemos evidencias de conflictos entre las diversas corrientes. Los conflictos comenzaron cuando algunas ideas amenazaban con socavar la identidad cristiana: por ejemplo, el inicio de un cierto docetismo en las comunidades joánicas o un antipaulinismo ebionita que desfiguraba no sólo la imagen de Pablo, sino también la de Cristo. 
De esto que hemos dicho, ¿podemos hablar de "diversos cristianismos" en Éfeso? Se puede hablar perfectamente de diferentes formas de vivir el cristianismo, pero no de diferentes cristianismos. ¿Cuál sería la esencia del cristianismo? Unos setenta años después del paso de Ignacio por Éfeso, San Ireneo comienza a hablar de una regula fidei. Esta regla de la fe no es la síntesis de las doctrinas contenidas en el Nuevo Testamento, sino la suma de las confesiones de fe profesadas en el Bautismo y en la liturgia, testimoniadas, por supuesto, en el Nuevo Testamento, pero que existían incluso ya antes de que aparecieran los primeros escritos que más tarde entrarían a formar parte del canon neotestamentario. La Regula Fidei se desarrollará posteriormente en el Credo. Podríamos decir, aunque exagerando un poco, que también habríamos tenido el credo incluso si no hubiera existido el Nuevo Testamento. La regla de la fe fue un producto de la tradición y de la práctica de la Iglesia; no fue producida por el Nuevo Testamento, pero fue la que sirvió para cualificar el canon.

Vamos a intentar explicarlo mejor: Bauer decía que el canon del NT había sido inventado para imponer la ortodoxia por parte de Roma. Nada podría estar más lejos de la verdad. El canon nace de la lectura de escritos considerados como apostólicos en las comunidades creyentes desde el inicio. Eran leídos públicamente, a diferencia de los libros secretos gnósticos. Además de la tradición de la apostolicidad y de su lectura pública, también se requería la aceptación universal de estos escritos; pero el último criterio fue el más decisivo e importante: cada composición que parecía contraria a la Regula Fidei, a priori era descartada. El canon, por lo tanto, era una garantía de la ortodoxia, no su causa. Por otra parte, con el canon podemos empezar a hablar de catolicidad, catolicidad en el sentido de universalidad, y universalidad no tanto geográfica sino teológica. Hemos visto las principales corrientes cristianas en la iglesia de Éfeso y en otras iglesias, a saber, la judeocristiana, la paulina, la petrina y la joánica. Pues bien, la unión de nuestros cuatro Evangelios representa la concordia de estas cuatro corrientes en una única confesión de fe. Según la tradición, Marcos acompañó a Pedro, Lucas a Pablo, Mateo representa el judeocristianismo moderado, mientras que Juan la corriente que lleva su nombre. El resto de los libros del Nuevo Testamento pertenecen a alguna de estas corrientes. Por tanto, el cristianismo, ortodoxo y católico, es todo lo que se enmarca dentro de este universalismo y es fortalecido por la confesión de la fe bautismal, la liturgia, por la fama de la apostolicidad, por los testimonios carismáticos, y no menos por el sensus fidei de los creyentes sencillos. Por lo tanto, una gran variedad de teologías, de tradiciones y de formas de vivir la fe, pero un solo cristianismo con su propia identidad ya desde los inicios. 
Podemos plantearnos otras cuestiones: ¿Cuál es la diferencia entre herético y no cristiano? La herejía no es un simple error de fe; más bien, se trata de una doctrina que no se ajusta a las normas de la fe, afirmada con obstinación y, a menudo, convertida en bandera de un grupo que se separa de la comunidad central. El hereje se sale del marco de la ortodoxia, pero permanece, de algún modo, todavía siendo cristiano; una vez superado el error y la obstinación, vuelve a ser ortodoxo.

Definir los parámetros del "no-cristiano" es un poco más complicado. Cristiano no es todo aquel que venera a Cristo. El Corán habla bien de Cristo y de María, pero no por eso es cristiano. El gnosticismo ¿era o no cristiano? Aquí encontramos tal vez el criterio decisivo para distinguir entre cristiano y no cristiano. Tanto el cristianismo patrístico como el gnosticismo estaban vinculados con la filosofía griega; sin embargo, mientras que el cristianismo partía del a priori de la regla de fe, aunque hacía uso de la filosofía griega, sin embargo rechazaba todo lo que amenazaba la integridad de esta regla. Por su parte, el gnosticismo partía del a priori de una teosofía ecléctica, y, aunque incorporaba doctrinas y relatos cristianos, rechazaba todo lo que no se ajustaba a ese a priori filosófico. De ello se desprende que no se puede hablar de "cristianismos" eiusdem iuris en los primeros siglos, si deseamos incluir entre ellos incluso el gnosticismo.

Esto aparecerá más claro si regresamos al evangelio de Judas. Este documento contiene muchos elementos que pertenecían a la tradición cristiana: Jesús, los doce apóstoles, la revelación, los milagros de Jesús e influjos de los relatos sinópticos. Pero todo esto estaba al servicio de otra regula, no sólo contraria a la cristiana, sino completamente opuesta a ella. En mi opinión, este evangelio no merece el título de hereje, porque no es simplemente una desviación de la regla de la fe, sino una modificación profunda y completa, integrado en un sistema religioso que partía de principios no cristianos. No se trata de "no cristiano" en el sentido de pagano, pero ni siquiera se le puede catalogar en la categoría de los cristianismos perdidos de Ehrman.

De hecho, fue precisamente esta ambigüedad de lenguaje la herramienta en manos de los gnósticos para hacer proselitismo entre los cristianos. Ellos se infiltraron en las asambleas y, hablando un lenguaje que parecía cristiano, invitaban a la gente inculta a sus propias reuniones donde se les revelaba todo el contexto del discurso iniciático. Es la técnica de las sectas modernas y de ciertas ideologías políticas que juegan con las palabras "democracia" y "libertad". Ireneo desvelará y nos trasmitirá todo el contexto de los gnósticos. 
Hasta ahora nos hemos centrado en los gnósticos y ebionitas para distinguir a los cristianos de los no-cristianos, pero aún persiste el problema planteado por Bauer sobre el surgimiento de la ortodoxia. Además de algunos de los argumentos ya expuestos, trataré de ofrecer una lista de doce factores que contribuyeron a que prevaleciera la ortodoxia en los dos primeros siglos.

1. En primer lugar, se venera el Antiguo Testamento, a diferencia de Marción y de varios grupos gnósticos. Esto genera la autoconciencia de la Iglesia de ser la heredera y también la continuadora de Israel. La interacción de la profecía y el cumplimiento vincula más estrechamente a la iglesia al antiguo pueblo de Dios. El uso de la tipología y de la alegoría en la interpretación de las leyes y las instituciones de Israel satisface los anhelos de los creyentes. Por otro lado, la Iglesia rechaza la circuncisión y la estricta observancia de la Torá como medios necesarios para la salvación, al tiempo que insiste en la obligatoriedad del decálogo para establecer una moral universal. En esto se distingue de los ebionitas. Del Antiguo Testamento hereda el monoteísmo que mantiene, aunque confiese la divinidad de Cristo.

2. La aparición del episcopado a finales del siglo primero, que reivindica la autoridad de la enseñanza de los apóstoles, cuyo profeta era Ignacio, sin duda contribuyó a unir las diferentes corrientes en las iglesias particulares o locales. Por otra parte, la constante correspondencia entre las iglesias y los obispos generaba una red de intercambio doctrinal al modo de los vasos comunicantes, porque los más avanzados ayudaron a los más lentos, pero, al mismo tiempo, esos se vieron frenados por comunidades más prudentes. La red de correspondencia contribuyó a la unidad y afirmó la universalidad de la nueva religión. Tampoco se puede olvidar el papel relevante que desempeñaron el carnet de hospitalidad (hospitalitatis) y lás colectas para las comunidades más pobres, en particular la de Jerusalén, la iglesia madre incluso después de su destrucción. El gnosticismo, sin embargo, estaba fragmentado: Ireneo dice que se podían contar tantos gnosticismos cuantos eran sus integrantes.

3. Es una constante la reivindicación de la enseñanza de los apóstoles y de sus discípulos inmediatos; poco a poco esto crea un depositum fidei (depósito de la fe) que se transmite a las generaciones posteriores. Esta transmisión era pública, a diferencia del secretismo de los gnósticos. 
4. Como ya se mencionó anteriormente, era necesario establecer la regula Fidei; a partir de Ireneo, existe un criterio de discernimiento entre lo que está en consonancia con la tradición apostólica y las aberraciones doctrinales.

5. El equilibrio entre la profecía y los oficios institucionales, que constituirá un problema constante en la Iglesia, la distingue, de una parte, de la corriente montanista, y de la otra parte, de los ebionitas, quienes carecían de la estructura institucional y de su comprensión de la profecía.

6. También hemos hablado del surgimiento del canon del Nuevo Testamento. Dada la multitud de libros gnósticos compuestos en el siglo segundo, esta medida se había convertido en necesaria. Sin embargo, la fijación del canon no provenía de una decisión eclesiástica, de hecho, las listas oficiales de los libros canónicos no surgieron sino siglos más tarde. Algunos autores atribuyen el canon a Marción, quien, además de suprimir el Antiguo Testamento, había aceptado solamente el evangelio de Lucas y diez epístolas de Pablo, y expurgadas por él mismo. La reducción del número de evangelios provocó una reacción en las comunidades, acostumbradas a leer cuatro, particularmente Mateo, y más cartas, es entonces cuando se comenzó a enumerar los libros autoritativos para los cristianos. Pero Marción había provocado una reacción aún mayor porque con su "canon" se había reducido el cristianismo al paulinismo, mutilando el catolicismo que hemos mencionado anteriormente.

7. Tampoco se puede olvidar el factor del diálogo con la filosofía griega, diálogo al servicio de la fe, sin ser absorbido por esta filosofía. Así, la fe ha encontrado una defensa tanto contra el fundamentalismo como también contra la especulación fantástica y mitológica de los gnósticos.

8. Además, basta leer el Pastor de Hermas para incorporar a esta lista de factores de la ortodoxia, el elemento de una moral rígida, pero con la posibilidad de perdón por medio de la conversión. Por su parte, el gnosticismo, había sustituido los conceptos del bien y el mal por el conocimiento y la ignorancia, y los montanistas negaban a ultranza el perdón.

9. Incluso el martirio contribuyó al surgimiento de la ortodoxia. Los gnósticos rechazaron el valor del martirio al igual que habían rechazado el valor de la muerte y de la humanidad de Jesús; esto ya lo habíamos señalado en el Evangelio de Judas. A ello, se puede añadir la insistencia de los creyentes en la historicidad de Jesús y de la Iglesia (Ekklesia no era un eón, 
como en los gnósticos). Es este un elemento que distingue a los evangelios cristianos de los evangelios gnósticos.

10. El desarrollo del culto cristiano y del sistema sacramental era el terreno en el que la lex orandi y la lex credendi se explican de forma recíproca. El gnóstico, nacido y predestinado espiritualmente, no tenía necesidad de orar.

11. Por otra parte, las antiguas confesiones de fe de Jesús como Hijo del hombre distinguían a los creyentes frente a los docetas; la confesión del Kyrios Hijo de Dios, los distinguían de los ebionitas y la confesión del monoteísmo los diferenciaba de los seguidores de las religiones paganas. Ésta es la identidad del cristianismo ortodoxo.

12. Una última observación referente a la tesis de Bauer, quien afirma que, en las iglesias locales de la antigüedad, la herejía precedió a la ortodoxia, en concreto con respecto a los marcionitas y a los gnósticos. Es cierto que la propagación del gnosticismo en el siglo segundo fue casi universal. Sin embargo, los gnósticos difundían su doctrina no entre los paganos, sino entre los miembros de la Iglesia. Evidentemente, esto supone que los cristianos ya existían allí, y que las iglesias eran iglesias pre-gnósticas. Pero no se puede asumir que todos los "cristianos apostólicos" se mantuvieran firmes y constantes en su fe. En una familia convertida porque el padre de familia se hubiera convertido, no se puede suponer que todos los miembros de la familia tuvieran ni la misma convicción ni la misma comprensión, y con frecuencia eran los miembros más débiles quienes sucumbieron a la propaganda gnóstica, como también sucede en nuestros días: los miembros más débiles son más vulnerables a los testigos de Jehová y a las sectas. La fenomenología religiosa se repite.

Concluyo con la observación de que en esta conferencia mo he querido apelar al factor sobrenatural en el desarrollo de la Iglesia, por lo que me he mantenido en el nivel puramente histórico de nuestros interlocutores. Tampoco es correcto, desde este punto de vista, hablar de "cristianismos" eiusdem iuris desde los inicios. Existe un cristianismo central cuya fuerza centrípeta era la tradición apostólica escrita, oral y litúrgica, que nosotros, como creyentes, atribuimos a la guía del Espíritu Santo según las palabras de Jesús: "Tendría que deciros muchas más cosas, pero no podríais entenderlas ahora. Cuando venga el Espíritu de la verdad, os iluminará para que podáis entender la verdad completa" (Juan 16,12). 